\title{
España y Portugal durante la segunda guerra mundial
}

\author{
M. ${ }^{A}$ Soledad Gómez de las Heras
}

ESTHER SACRISTÁN

Cuando las relaciones internacionales entran en franco deterioro en el escenario europeo, el entendimiento político entre España y Portugal presentaba a la Península Ibérica como un bloque relativamente unido ante la conflagración mundial. La política exterior de estos dos Estados durante la segunda guerra mundial se enmarca dentro de unas coordenadas, que son tenidas en cuenta por los diplomáticos de ambas naciones, de los beligerantes y neutrales: la coincidencia del talante político e ideológico de los regímenes de Salazar y Franco se sumaba a la importancia estratégica de la Península, que obligaba a un entendimiento entre ambos Estados, siempre amenazados por el peligro de un ataque proveniente del exterior.

La cordialidad peninsular se gestó durante la guerra civil española; de ahí la existencia de dos constantes que marcan las relaciones hispano-portuguesas frente al conflicto europeo: la deuda de gratitud que la España de Franco mantuvo con Portugal ante la valiosa ayuda de Salazar a los insurgentes contra la República Española pero, también, las alianzas diplomáticas divergentes de los dos países peninsulares con bandos antagónicos en la guerra europea. Mientras Portugal perduró en su secular alianza con Inglaterra, España inició, precisamente desde su guerra civil, estrechas relaciones con Alemania y, sobre todo, con Italia. La política exterior de Portugal persistió firme, durante toda la guerra, en una línea de neutralidad de la que intentó que no le desviara España, la cual, a menudo, pareció que la iba a abandonar como consecuencia de sus simpatías por las potencias del Eje y la presión de ellas, principal- 
mente de Alemania. Ya en abril de 1938, cuando la situación internacional se agravó por la crisis de Checoslovaquia ${ }^{1}$, Salazar, ante la posibilidad de que se produjera un conflicto europeo a gran escala, intentó maniobrar buscando una posición diplomática para Portugal que garantizara su neutralidad en caso de guerra y atrajera a España a una postura semejante. En ese momento reconoció oficialmente como legítimo Gobierno de España al formado recientemente por Franco en Burgos $^{2}$. Con esta decisión se creaba en la Península una identidad ideológica que salvaguardaba tanto la individualidad portuguesa como su alianza con Inglaterra. Salazar esperaba que esta identidad entre España y Portugal reforzase la posición peninsular en Europa, vista la probable victoria nacionalista en la guerra civil y, además, evitara una excesiva decantación española hacie el Eje. Así se sentaron las bases futuras por las que debian discurrir las relaciones peninsulares: una buena amistad interna basada en la identidad común y en el respeto mutuo y, frente al exterior, un bloque peninsular que actuaría al unísono basando su fuerza, ante las presiones europeas, en su posición estratégica y en esa unidad de criterios. Esa identidad estaría forjada en un pasado común, la identificación con los ideales cristianos de vida, los lazos tendidos con América hispana y un mantenimiento de la paz peninsular frente a los conflictos europeos. El punto débil del proyecto de Salazar estribaba, sin embargo, en que España y Portugal sostenían relaciones exteriores antagónicas en el caso de estallar una guerra en Europa. Para Portugal la alianza con Inglaterra era el pilar fundamental de su política exterior; en España el Gobierno del General Franco estaba siendo decisivamente ayudado a ganar la guerra por italianos y alemanes.

Ante la posibilidad de verse involucrado en un conflicto de ámbito europeo y con la amenaza de Francia sobre la frontera de los Pirineos y el Marruecos español, la política exterior española viró en 1938 hacia Portugal con un relativo alejamiento de Alemania e Italia ${ }^{3} \mathrm{o}$, al menos, recalcando la neutralidad y la independencia respecto de esos países. Para la propia España de Franco resultaba necesario estrechar lazos con el país vecino y asegurar que por la frontera portuguesa no habría agresión alguna. En julio de 1938 Nicolás Franco, desde su embajada en Lisboa, sugirió buscar una fórmula que le permitiera un mayor estrecha-

' Dez annos de politica externa. A naçao portuguesa e a Segunda Guerra Mundial. Vol. N. ${ }^{\circ}$ 5. Doc. N. ${ }^{\circ} 1604$, pág. 259 y ss.

${ }^{2}$ AMAE, leg. 1051. Exp. 10.

${ }^{3}$ M.S. GOMEZ DE LAS HERAS, "El Tratado de No-Agresión Hispano-portugués de 19 de marzo de 1939 " Historia 16, N. $^{\circ} 130$, págs. 11/18. 
miento de relaciones con Portugal y garantizar su posición independiente ${ }^{4}$. Así se iniciaron las conversaciones entre el embajador portugués, Teotonio Pereira, y Jordana, ministro de Asuntos Exteriores, encaminadas hacia la firma de un tratado de amistad y no-agresión ${ }^{5}$.

A simple vista parecía que un acuerdo de esta naturaleza reforzaría la política que Salazar intentaba imponer en la Península de amistad interna y paz exterior. Sin embargo, frente a la evidente prisa que el Gobierno de Burgos demostró por concluir el tratado, del cual llegó a presentar un borrador ${ }^{6}$, los portugueses estuvieron sólo inicialmente dispuestos a garantizar verbalmente su simpatía por la causa nacionalista y «la relativa facilidad en mutuas seguridades en el caso de que España pudiera mantenerse neutral» ${ }^{7}$. El Gobierno de Salazar dio, pues, largas mostrándose muy prudente a la hora de decidirse a concertar un tratado que pudiera interpretarse como un alejamiento de su alianza con Inglaterra. Tan sólo dio luz verde el Gobierno portugués a la discusión de los artículos del tratado el 8 de febrero de $1939^{\circ}$, cuando las circunstancias internas y externas de España se consideraban propicias; entonces prácticamente la guerra civil estaba terminada; tanto Inglaterra como Francia reconocieron de jure al Gobierno nacional en este mismo mes, y existía una razonable seguridad de que las tropas de Italia y Alemania abandonarían el territorio español en cuanto terminara la guerra. Hay que señalar que, si bien la iniciativa del tratado de amistad y no agresión había sido española, Portugal tomó inmediatamente las riendas eligiendo el momento para iniciar las negociaciones y también en la propuesta del articulado y la discusión del mismo ${ }^{9}$. El Tratado de Amistad y No-Agresión se firmó el 17 de marzo de 1939 y el día 28 las tropas nacionales entraron en Madrid, dando prácticamente por terminada la guerra civil. Salazar tenía que apresurarse en dejar establecida su idea del bloque peninsular antes de que la contienda española pudiera alterar alguna de las premisas de su política exterior; además, la conclusión del tratado con España reforzaría su prestigio frente a Inglaterra: Portugal había apostado frente al resto de europa por la victoria de Franco y una política afín con la España nacionalista y había acertado en sus previsiones.

\footnotetext{
${ }^{4} A M A E$, leg. 1058. Exp. N. ${ }^{05} 6$ y 8.

${ }^{5}$ Dez annos..., op. cit., Vol. 5, págs. 444 y ss. Doc 1756-1761, 1766-1768, 1773.

AMAE, leg. 1058. Exp. 6.

${ }^{7}$ Dez Annos..., op. cit., Vol. 5. Doc. 1754, pág. 445.

${ }^{8}$ Ibidem. Doc. 1908, pág. 608-610.

${ }^{9}$ M. S. GOMEZ DE LAS HeRAS, op. cit., pág. 12 y ss.
} 
La firma del tratado hispano-portugués de amistad y no agresión se vio completamente ensombrecida por la declaración pública, meses después, de la adhesión española al Pacto Antikomintern ${ }^{10}$. La alineación que este pacto revelaba entre España y Alemania e Italia, modificaba totalmente la imagen de independencia y neutralidad que Portugal pretendía ofrecer a Europa de la España con la que acababa de concluir el tratado y dificultaba el proyecto salazarista de "bloque peninsular» apareciendo en el horizonte nuevamente el peligro de las alianzas contrapuestas de los dos países. Así se apreció en Europa y América, aunque las representaciones diplomáticas de Salazar lo explicaran tan sólo como una muestra de gratitud española, respecto a los países que tanto le habían ayudado a ganar la guerra ${ }^{11}$.

Cuando la Guerra Mundial estalló el 1 de septiembre, España y Portugal se declararon, como era previsible, neutrales, pero la manera de plantear esa neutralidad no era en modo alguno idéntica. El Gobierno Salazar mantuvo su neutralidad dentro de la alianza con Inglaterra, mientras que España estaba mucho más pendiente de la marcha de los acontecimientos y próxima a las posturas del Eje. Así se hizo evidente cuando la guerra llegó hasta las mismas fronteras peninsulares e Italia decidió entrar en la guerra al lado de Alemania. Para Portugal era necesario encaminar a la Península lbérica a una reafirmación de la neutralidad; incluso trató de que España y Portugal hicieran simultáneamente la declaración oficial de la misma. Era razonable suponer que la reacción española fuera positiva a esta iniciativa, pues, aparte de las relaciones inmejorables entre los países ibéricos ${ }^{12}$, los españoles no había dejado entrever hasta el momento en sus relaciones diplomáticas que fuesen a adoptar una política distinta a la portuguesa.

Sin embargo, desde mediados de junio el Gobierno luso modificó su opinión sobre la España de Franco. Varios factores contribuyeron a ello: desde la manera distante como pasaron a ser tratados los representantes

10 AMAE, Leg. 1051. Exp. 8. El diario Da manha de Lisboa de 24 de Agosto de 1939 publicó un interesante artículo en que se comentaba que anteriormente habia «el frente de las democracias" y «el frente antikomintern» y -continúa- ahora sería más a propósito llamarlos «frente de paz»y «frente de guerra».

11 Aunque Salazar afirmó que había sido informado con anterioridad a la firma del Tratado, el Pacto Antikomintern fue firmado con carácter secreto el 21 de febrero de 1939, antes de la conclusión del Tratado de Amistad y No-Agresión luso-español.

12 El 10 de junio Franco fue condecorado con el Gran Collar de la Torre y la España, importante condecoración portuguesa. 
portugueses, hasta la opinión de la prensa controlada por Serrano Súñer que abrió una campaña contra la alianza inglesa de Portugal. No es de extrañar que en varias capitales europeas corrieran rumores de un cambio de intenciones de Franco respecto del conflicto mundial. La declaración española de no-beligerancia ${ }^{13}$ frente a las nuevas circunstancias de guerra, decreto que no había sido dado a conocer previamente al Gobierno de Lisboa, obligó a Salazar a optar por no hacer una declaración aislada de neutralidad. De hecho lo que conocemos acerca de esa declaración de no-beligerancia hace pensar que las autoridades españolas la concebían, como había ocurrido en el caso de Italia, como una prebeligerancia, es decir, un paso previo a la entrada en la guerra. Volvía, pues, el conocido peligro de las alianzas contrapuestas.

El Gobierno de Franco quedó deslumbrado por la guerra relámpago alemana. El impensable derrumbamiento francés dio alas a un sector de la clase dirigente española que esperaba obtener de la Nueva Europa, que surgiera de la guerra, una serie de reivindicaciones territoriales ${ }^{14}$. Franco pensaba que la guerra sería corta y no deseaba ni podía participar en ella de un modo muy actico, pues la situación económica y militar española tampoco lo permitía; lo que sí deseaba era estar lo suficientemente próximo al Eje como para unirse al carro de la victoria en el momento oportuno, logrando, con ello sus reivindicaciones en Marruecos, Gibraltar y colonias africanas ${ }^{15}$. La declaración de no beligerencia española era el primer paso dado en este sentido.

En estos momentos constituia una amenaza palpable para Portugal que las tropas alemanas pasaran los Pirineos para tomar Gibraltar y, posiblemente, las costas atlánticas de Portugal, sin que España se opusiera a ello o con su apoyo como aliado ${ }^{16}$. En todo caso, la situación en que quedaba Portugal era muy mala; temía por una parte una posible invasión alemana a través de España, mientras que, de otro lado, su alianza con Inglaterra ponía también en peligro su integridad territorial, puesto que el Reino Unido podía considerar la situación portuguesa como

\footnotetext{
13 Decrero-Ley de 13 de junio de 1940.

${ }^{14}$ Estas reivindicaciones se contuvieron en el libro de Areilza y Castiella, Reivindidaciones de España.

${ }^{15} \mathrm{El} 14$ de junio las tropas españolas entraron en Tánger bajo pretexto de garantizar su independencia. El 16, Virgón llevó la carta de Franco a Hitler en la cual se ofrecía la entrada de España en la guerra a cambio de reivindicaciones territoriales en Marruecos.

${ }^{16}$ Esta interpretación se recoge en la documentación diplomática portuguesa de todo el período (Mayo a agosto de 1940). Dez annos..., op. cit., Vol. 7. Doc. 950-963 y ss.
} 
potencialmente peligrosa e invadir el país para garantizar su libertad frente a intentos de anexión por parte del Eje. La amenaza no afectaba solamente a Portugal en su territorio peninsular, sino que se ampliaba a los archipiélagos insulares ${ }^{17}$.

El margen de maniobra que tenía el Gobierno de Salazar y la propia Gran Bretaña para aliviar la presión que ejercía el Eje sobre la península era muy corto ${ }^{18}$. Se hizo necesario crear unos procedimientos que obligaran al Gobierno español a la neutralidad. Uno de ellos, la presión económica, la ejerció Inglaterra en combinación con Portugal ${ }^{19}$, convencida de que la aproximación entre los dos países ibéricos frenaría los intentos de desviación de la neutralidad. Entre mayo y junio de 1940, se negoció un acuerdo de clearing por el cual España recibiría 100.000 toneladas de trigo a cambio de que el Gobierno de Salazar pudiera obtener del espanol ciertas garantías acerca de su neutralidad ${ }^{20}$. Se trató, al mismo tiempo, de otros posibles acuerdos, por los cuales se venderían a España productos coloniales portugueses que se pagarían por medio del clearing angloespañol. Otro método de mantener a España fuera del conflicto estuvo basado en las buenas relaciones diplomáticas entre los Gobiernos Lisboa-Madrid. Había en la política interna española un sector neutralista. De hecho, mientras la política exterior española se acercaba cada vez más al Eje Berlín-Roma, sus pasos se acompañaron de garantías verbales dadas a los portugueses de mantener el país alejado de la guerra. Así, el 13 de junio de 1940, mientras España declaraba oficialmente su cambio de la neutralidad a la no beligerancia, al embajador español en Lisboa, Nicolás Franco, transmitió un mensaje de su Gobierno al portugués: «la actitud adoptada ahora por el Gobierno español para definir la situación de España frente a la guerra no comporta el más pequeño desvío en la línea de conducta hasta ahora seguida de la más perfecta neutralidad» ${ }^{21}$, seguridad que volvió a ser reafirmada por Beigbeder, Mi-

17 Los documentos diplomáticos portugueses muestran, durante este período, la preocupación por la situación de los archipiélagos atlánticos. Dez annos..., op. cit., Vol. 7. Doc. 762 y Doc. $N^{\circ} 1014$.

18 Monteiro, embajador portugués en Londres, informó durante junio de 1940, que el propio Alba está preocupado porque no sabe si el Gobierno podrá resistir las presiones del Eje.

${ }^{19}$ AMAE, Leg. 2075. Exp. 8. Acuerdos comerciales entre España y Portugal en los que queda patente el arreglo triangular hispano-anglo-portugués.

${ }^{20}$ Dez annos..., op. cit., Vol. 7. Doc. 765.

21 El 19 de julio Nicolás Franco, en su discurso en Lisboa en la conmemoración del Cuarto Aniversario de la Revolución Española afirmo que «hoy más que nunca Portugal y España caminan juntas y con la perfecta y completa inteligencia y armonía». Diario de Noticias, 19 de junio de 1940. 
nistro español de Asuntos Exteriores, al embajador Teotonio Pereira, el dia 2 de julio en Madrid ${ }^{22}$. Si estas garantías españolas buscaban no perder una línea de conexión con Portugal, también querían encontrar por parte portuguesa la recíproca garantía de que sus costas no fueran a ser invadidas por los aliados, mientras, la garantía lusa ayudaría al Gobierno de Madrid a fortalecer su posición frente a Alemania e Italia ${ }^{23}$. Otro sector de la política interna española, encabezado por Serrano Suñer, estaba dispuesto a entrar en la guerra a favor del Eje y a presionar a Portugal para que adoptara una postura benevolente hacia el mismo o incluso a someterlo a su influencia. Esta aparentemente contradictoria política española, que por un lado se aproximaba al Eje mientras por otro reafirmaba las garantías de neutralidad tendidas a los aliados vía Portugal, da una imagen de la situación en la que se encontraba el régimen español de la época: demuestra su falta de unidad interna y nula coincidencia de criterios en política exterior. Un ejemplo óptimo de ello lo constituye el inicio de las negociaciones hispano-lusas, que culminarían en la firma del protocolo adicional al Tratado de Amistad y No-Agresión. Por una parte, el Ministro de la Gobernación, Serrano Súñer, en la conversación con el embajador portugués el 28 de junio ${ }^{24}$, expuso su criterio, según el cual, para Portugal, la alianza con Inglaterra constituía un peligro, ya que ésta podría ser utilizada por los alemanes como pretexto para invadir la península. En consecuencia, el modo de reforzar su capacidad de resistencia frente a una posible agresión era ir más allá del Tratado de Amistad y No-Agresión, firmando una alianza entre los dos Estados, España y Portugal, que garantizase, hasta con las armas, la seguridad de sus territorios. Lo que propuso Serrano a los portugueses era un alejamiento de la alianza británica a cambio de una unión más estrecha con España. En el fondo se trataba de un enfeudamiento de la posición lusa a la española, con lo que ello suponía de pérdida de independencia.

${ }^{22}$ Según el embajador portugués, “Me aseguró que España correspondería enteramente a nuestros sentimiento y que haría todo lo posible para no quebrar el Bloque de Neutralidad de la Península«.

${ }^{23}$ Telegrama de Oliveira Salazar a su embajador en Londres, Armando Monteiro, con orden de que transmitiese su contenido al Ministro de Asuntos Exteriores inglés. Doc. N. ${ }^{\circ}$ 930, págs. 179 a 181: «España presenta, imprecisamente y a título no oficial, la idea de cualesquiera garantías que pudiesen darse de no utilización de nuestras costas por Inglaterra, o de cualquier refuerzo del Tratado de Amistad y No-Agresión que fortaleciese la posición de España delante de Alemania e Inglaterra y le permitiese resistir las presiones económicas».

${ }^{24}$ Pereira, Memorias, Vol. 2, págs. 230-231 y Halstead «Consistent and total peril fron every side. Portugal and its 1940 portocol with Spain». Iberian Studies, Vol. III, N. ${ }^{\circ}$ 1, págs. 17 y ss. 
De hecho la postura de Serrano Súñer venía a ser una vuelta a la tradición iberista; en conversaciones posteriores con los dirigentes alemanes les sugirió que un país tan pequeño como Portugal había perdido su razón de ser en la nueva Europa.

Los portugueses, como ya lo habían hecho en la negociación del tratado de Amistad y No-Agresión, tomaron la iniciativa de buscar un nuevo acuerdo con España, mucho más acordé con el pensamiento luso sobre lo que se debía hacer frente al peligro de invasión peninsular. Para ello recurrieron, además, a un nuevo intelocutor. La fórmula propuesta por el secretario General del Ministerio de Negocios Extranjeros, Teixeira de Sampaio, de "entente cordiale" permitía que, en caso de emergencia, el entendimiento se limitase a una simple colaboración diplomática, que también podía entenderse como una verdadera alianza, pero cuando el embajador Nicolás Franco recibió el primer borrador de protololo, Salazar había transformado las palabras "entente cordiale», que podrían generar compromisos no deseados, en una simple «concertación», fórmula menos comprometida y de términos tan imprecisos, que podía cubrir una mera fórmula de cortesía. Por otro lado y sobre todo, los interlocutores españoles con los que Portugal iba a discutir los términos del Protocolo Adicional, fueron, en adelante, el propio general Franco y el ministro de Asuntos Exteriores Beigbeder, en Madrid, y, en Lisboa, el embajador Nicolás Franco. Serrano Súñer, por tanto, no tuvo la oportunidad de intervenir en la negociación.

Lo esencial del punto de vista del Jefe del Estado Español estribó en que, en efecto, Portugal y España necesitaban unir sus fuerzas para enfrentarse a un posible peligro de invasión peninsular. Franco afirmó que los alemanes no tenían interés en llegar hasta Portugal, si éste a su vez no era tomado por los ingleses; el peligro de invasión, por tanto, venía, según él, del lado británico. España estaba dispuesta a defender tanto su territorio como el portugués por medios diplomáticos, o por las armas, si un hecho como éste se produjera, aunque viniese del lado alemán. Añadió, además, que una concertación prevista en estos términos tendría que ser secreta. Por su lado, Salazar, con el borrador del Protocolo anteriormente presentado, había dejado bien sentado que no quería asumir compromisos diplomáticos o militares claros que pudiesen comprometer la libertad de acción portuguesa o su alianza con Gran Bretaña; con ello quedó fuera de discusión el que pudiera firmarse un Protocolo "secreto" con España, pues el secreto sólo podría traer malas interpretaciones. 
La idea portuguesa iba encaminada a eliminar riesgos por medio de una declaración de concertación genérica pero clara y públicamente expuesta, que preservara a España y Portugal de posibles invasiones, manteniendo el Status quo de neutralidad para la Península, con un mínimo de compromiso potugués ${ }^{25}$.

Franco terminó admitiendo la línea argumental portuguesa con tal de que la concertación incluyese implícitamente la reivindicación española de Gibraltar y así se incluyó en el texto definitivo del Protocolo Adicional; el ámbito del protocolo se refería a "siempre que se prevean o verifiquen actos que por su naturaleza puedan comprometer la inviolabilidad de los territorios metropolitanos o constituir peligro para la seguridad o independencia de una u otra de las dos partes". Mediante esta fórmula España dejaba la puerta abierta a sus reivindicaciones territoriales y, a su vez, Portugal reconvertía el Tratado de Amistad y No-Agresión en una fórmula más dinámica, que mantuviese la tan preciada idea salazarista del «bloque peninsular» ${ }^{26}$.

La repercusión en Europa del nuevo acuerdo peninsular fue por completo positiva, pues tanto unos como otros interpretaron la firma del Protocolo Adicional a su manera y de acuerdo con sus intereses. Los ingleses aceptaron la interpretación portuguesa de que se trataba de un nuevo reforzamiento de la alianza peninsular para mantener la neutralidad de España y Portugal frente a las presiones del Eje. Alemania e Italia, por su parte, creyeron que la renovación de la unidad peninsular se debía a que España atraía a Portugal hacia su línea de política exterior, apartando a esta última de su alianza con Inglaterra. «Todos contentos", le comentaba Beigbeder a Teotonio Pereira ${ }^{27}$. Si en España nadie puntualizó versiones tan contradictorias sobre el verdadero alcance del Protocolo Adicional, tampoco en Portugal nadie pensó que fuese necesario hacerlo. De hecho habría siclo Salazar el triunfante en cuanto que habría impedido una mediatización como la intentada originariamente por Serrano Súñer.

${ }^{25}$ La documentación portuguesa es mucho más completa que la española en cuanto a la negociación del Protocolo Adicional de 1940. Para seguir las líneas argumentales tanto portuguesas como españolas vid. Dez annos. Vol. 7, págs. 216 a 219, 247 a 249, 250 a 252, 294 a 297, 301-302.

26 Vid. A. Telo, Portugal na Segunda Guerra. Págs. 211-214.

${ }^{27}$ Dez annos..., op. cit., Doc. 1081, págs. 343-344. 
Paradójicamente Hitler tenía una visión muy realista sobre Portugal que no se podía separar de Inglaterra, pues en ese caso vería sus Islas inmediatamente ocupadas; por ello, era inútil ejercer presiones diplomáticas sobre Lisboa. El problema portugués - pensaba - seria resuelto militarmente cuando se atacase Gibraltar. Alemania, por todo ello, no presionó a Portugal, manteniendo las relaciones diplomáticas a un nivel cordial y casi amistoso. Por el contrario, fue continuo el crecimiento de las presiones sobre el régimen español con un solo objetivo dirigido a la toma del Peñón, que para Hitler tuvo un interés primordial durante un período corto y de forma especialmente intensa entre septiembre de 1940 y febrero de 1941. Después de estas fechas Hitler se convenció de que el Gobierno español no estaba interesado en entrar en guerra y exigía demasiado a cambio; por lo tanto, no merecía la pena violentar su neutralidad para atacar Gibraltar. La insistencia alemana fue cediendo en favor de nuevos planes militares que ya no se ocupaban de la zona occidental, sino de la invasión de Rusia ${ }^{28}$.

El Gobierno de Lisboa pudo haberse sentido molesto con la actitud española que, cuando menos, no le ofrecia información sobre unos hechos potencialmente peligrosos para la seguridad peninsular ${ }^{29}$. Pero la reacción de Salazar fue otra: convencido de que si España tenía dos opciones, «ser beligerante o neutral», Portugal sólo podía ser "neutral u ocupado", juzgó como único camino viable el reforzamiento de la neutralidad protuguesa. Por eso dio comienzo a una campaña de propaganda con el fin de explicar las ventajas que ofrecía un Portugal neutral para todo el mundo, tales como ser el último puerto seguro en Europa que garantizaba las comunicaciones entre los Continentes americano y europeo. Frente a la actitud marcadamente «pro-Eje» de España, Salazar adoptó una política benevolente para Franco. Se negó a creer que las declaraciones de los dirigentes españoles, la prensa elogiosa con el Eje o las continuas facilidades dadas a italianos y alemanes, fuesen a conducir a su vecino necesariamente a la guerra. Su política se basaba en la amistad entre los dos paises peninsulares y en la seguridad de que

${ }^{28}$ Para más información sobre esie período y sobre las presiones recibidas por el Gobierno español vid. TUSELL/Garcia QUEIPO dE LLANo, Franco y Mussolini. La Política española durante la Segunda Guerra Mundial. Págs. 102 a 135 . Véase también A. TELO, op. cit., pág. 273-388 y 415-426.

${ }_{29}$ La documentación diplomática española y portuguesa no se da cuenta de que se informara previamente al Gobierno de Lisboa sobre las distancias visitas y encuentros mantenidos entre España y los países del Eje. Existió, en todo caso, una explicación a posteriori de algunos de los encuentros y tampoco muy explícita. 
ésta garantizaría la integridad e independencia de la Península. Es, con todo, muy probable que esta interpretación fuera voluntarista y estuviera motivada por el deseo de Salazar de evitarse conflictos. De hecho España estuvo mucho más cercana a la intervención en la guerra que lo que admitió Salazar; no lo hizo por sus dificultades internas, la presión británica sobre los abastecimientos y el interés creciente de Hitler por Rusia. A Salazar, sin embargo, le convenía, para evitar una intervención británica, aceptar que España tenía una voluntad neutralista.

Los acontecimientos que se produjeron entre mediados y finales de 1942, el ataque alemán sobre Rusia en junio y la entrada de Estados Unidos en la guerra en diciembre, marcaron los nuevos cauces de la política bilateral peninsular. La reacción que tuvo España ante las nuevas convulsiones bélicas y políticas, pareció comprometer, por un momento, irremisiblemente al país con las potencias del Eje. Por un lado, Serrano Súñer ofreció a Alemania una división de voluntarios que irian a luchar al frente ruso, $y$, por otro, la prensa se presentó tan claramente anticomunista como antialiada y, el mismo Franco, en el discurso que pronunció ante el Consejo Nacional el 17 de julio, llegó a declarar que «se ha planteado mal la guerra y los aliados la han perdido", para, seguidamente, comparar la guerra civil española con la cruzada que ahora Alemania lanzaba sobre Rusia e identificar el comunismo con la democracia liberal y, finalmente, terminar lanzando un ataque directo contra los Estados Unidos, a los que acusó de intentar mediatizar políticamente la situación española. Esta virulenta reacción, que empeoraba las relaciones con los aliados, volvía a colocar al territorio peninsular como candidato a la beligerancia; sin embargo, Portugal, dentro de la más estricta neutralidad, consideró, acertadamente, que, a corto plazo, la campaña de Rusia alejaba el peligro inmediato de presión que el Eje ejercía en la Península, puesto que el teatro de las operaciones bélicas se trasladaba del Mediterráneo al Este. A partir de ahora para los países del Eje la posición de la Península tenía un interés relativo ${ }^{30}$.

La nueva invasión alemana obligó a Salazar a matizar su política exterior. Llegó a la conclusión errada de que Rusia no podría resistir

${ }^{30}$ Esto es lo que el embajador inglés en Madrid, Samuel Hoare, transmitió el Foreign Office. Según él, también los militares españoles le habían asegurado que la campaña de Rusia alejaba las posibilidades de intervención española. FO 371/26 939. 
mucho tiempo y sería Berlín quien dominara Europa desde los Urales a los Pirineos, con todos sus recursos humanos y económicos; el Presidente portugués sabía que Inglaterra pretendía arrastrar a la guerra a Estados Unidos, pero no creyó que eso fuese suficiente para derrotar a Alemania. Sobre estas convicciones Salazar elaboró una estrategia dirigida a estrechar relaciones con Alemania, especialmente de tipo económico, pero sin olvidar que Portugal no podía hostilizar a Londres, bajo pena de perder los Archipiélagos y el Imperio ultramarino y, por último, combatir las ambiciones americanas muy especialmente en el Atlántico, pues ya Roosevelt había manifestado interés por Las Azores, Cabo Verde y América Latina. La nueva estrategia de Salazar, que no difería tanto de la anterior, implicaba, como antes, un difícil equilibrio entre el Eje y los anglosajones. La entrada de Estados Unidos en la guerra tuvo una especial trascendencia para Salazar, pues abrió una nueva incógnita, sobre la situación en la que podrian quedar las islas atlánticas. Esta nueva situación pareció lo suficientemente grave a los dirigentes espanoles como para estrechar lazos con Portugal y para ureactivar» el Protocolo Adicional de 1940. En esas condiciones, se concertó con Oliveira Salazar un encuentro, que se celebró en Sevilla los días 12 y 13 de febrero de 1942, insistiéndose, sobre todo por parte portuguesa, en el carácter particular y no oficial de tal entrevista ${ }^{31}$.

Ambos estadistas se encontraban al frente de gobiernos dictatoriales, pero no estrictamente fascistas; eran neutrales pero en condiciones muy diferentes. Tenían obstáculos serios para su aprovisionamiento y una matización muy diferente de su política exteriór: España tenía acuerdos con Alemania e Italia y Portugal con el Reino Unido. El acuerdo al que se llegó, en definitiva, parece haber sido hacer cuanto estuviese en su mano para impedir que los aliados intervinieran en la Península. Serrano Súñer parece haber mantenido su política de 1940 basada en separar lo más posible a Portugal de su alianza con Inglaterra, por medio de un acuerdo más estrecho con España y, a través de ella, con el Eje. El propio Franco, que, en definitiva, llevó el peso de las conversaciones, ofreció ayuda española a Portugal en caso de que sus islas del Atlántico fueran invadidas; esa ayuda incluía también la oferta alemana de hacer los mismo en igual situación. Además se habló de una colaboración mutua en materia económica, en la lucha contra el comunismo y respecto a los

${ }^{31}$ La documentación portuguesa es muy parca en lo que se refiere a esta visita y la española inexistente. Las fuentes se encuentran en la documentación italiana. 
países hispanoamericanos. La significación de la reunión parece, por tanto, haber tenido una significación limitada.

La visita de Salazar a Sevilla mejoró sin duda las relaciones entre los dos países ibéricos al reactivar el Protocolo Adicional en lo que tenía más positivo: la búsqueda de soluciones comunes para neutralizar peligros externos. Desde el punto de vista de la repercusión internacional, este encuentro fue considerado como una reafirmación de la neutralidad peninsular que, por otro lado, Hitler ya no amenazaba. Según telegrafió el Duque de alba, la entrevista fue interpretada en la capital británica como el primer gesto público de alejamiento de España respecto a Alemania e Italia en busca de la neutralidad. Sin embargo, Franco demostró en el mismo mes, con un discurso donde permanecían sus simpatías ideológicas, que sus palabras iban destinadas a tranquilizar al Führer y disimular la maniobra que acababa de realizar. El Jefe del Estado español calificó, en el citado discurso, a Alemania como el baluarte que salvaba a Europa del comunismo, y a España como el primer país europeo que había provocado una guerra interna para erradicar este peligro de su propio suelo y que ahora tenía una división de voluntarios luchando en Rusia por los mismo ideales: "pero si hubiera un momento de peligro -decía-, si el camino de Berlín fuese abierto, no sería una división de voluntarios lo que alıí fuese, sino que sería un millón de españoles los que se ofrecerían" ${ }^{32}$.

Los dirigentes españoles no percibian, pues, la realidad de guerra de forma que fuese necesario variar la posiciòn "pro-eje» del país. Sin embargo, el camino se hizo necesario no mucho tiempo después. A finales de año, una vez más, la guerra tuvo en el Mediterráneo el foco principal de atención, dejando a España y Portugal en situación comprometida. Aun cuando la intención de los aliados no fue invadir ni España ni Portugal, y el desembarco llevado a sabo por ellos en el norte de África no partía de una actitud de agresividad frente a la España de Franco, ésta tenía razones para temer como consecuencia de la proximidad bélica. Sin embargo la sustitución de Serrano Súñer por Jordana, aunque exclusivamente basada en la política interior, ponía en condiciones de evolucionar a la diplomacia española en cuanto que la postura de este último era manifiestamente neutralista.

32 «Palabras del Caudillo». ABC 15 de febrero de 1942. 
También sufrió un viraje la política exterior portuguesa. En nota escrita por Jordana, tras una conversación mantenida con el Embajador de España en Portugal, afirmó: «De pocos días a esta parte ha habido un cambio fundamental en la política exterior de Salazar. Era norma ... lograr por encima de todo una aparente actitud de estricta neutralidad y ello había producido preocupación en los ambientes anglófilos, honda molestia en Inglaterra y la consiguiente satisfacción del Reich. Paulatinamente se han ido cerrando puertos hacia la Gran Bretaña y dificultándose la salida de productos de determinados artículos de primera necesidad ... pero hoy todo ha cambiado. El Gobierno portugués ha virado en redondo, firmando un nuevo Tratado comercial con Inglaterra que hace desaparecer todas las barreras y obstánculos. Al fin Salazar se decide a jugar, con todas sus consecuencias, a la carta británica. En Portugal se cree poder apostar ya, sin miedo a equivocarse, por el triunfo de las Naciones Unidas y subsiste el recelo y preocupación por España ...» ${ }^{33}$.

No es extraño que, en estas condiciones, se volviera a reactivar el Protocolo Adicional. Esta vez el encuentro se produjo en suelo portugués: el ministro español visitó Lisboa los días 18 al 22 de octubre de 1942. El Gobierno de Madrid necesitaba, ante todo, una argumentación ideológica que le ayudara a explicar, cara al exterior, su política diplomática frente a la guerra. España, se dijo ahora, había encontrado una tercera vía que la colocaba entre los aliados y el Eje, sin asumir las posiciones ideológicas de los primeros, pero apartándose todo lo posible del segundo. Por supuesto, no sólo no se olvidaba la amistad con Portugal, sino que ésta tenía especial sentido en las nuevas condiciones. El borrador que Jordana llevó a Lisboa para sus entrevistas estuvo redactado a la vista del evidente cambio de signo producido en la guerra de Europa y la necesidad de la Península de adaptarse a él. Las notas del ministro brindaban a los portugueses buscar esta nueva opción, además de sumarse a ella junto con los países que lo deseasen, suficientemente equidistante de los aliados y el Eje ${ }^{34}$. La base que sustentaría a estos países sería la doctrina católica que, en sí misma, tenía más valor intrínseco que la Carta del Atlántico. La intención más clara de la visita a Lisboa en diciembre de 1942 fue, por tanto, la búsqueda de un apoyo diplomático tan consistente como para que el régimen de Franco saliese airoso ante un final de guerra sin vencedores todavía claros. En cuanto a país neutral pero

33 AMAE. Leg. 1058, exp. 6.

${ }^{34}$ Borrador de Temas de Conversación del General Jordana para ser mantenidos con Salazar en su visita a Lisboa. Diciembre de 1942. AMAE. Leg. 1037, exp. 16. 
cercano a los aliados, Portugal era un pieza decisiva para la política española. También era importante la visita de Jordana para el Gobierno del país vecino, aunque los motivos eran diferentes. Parecía que, por fin, triunfaba la política exterior que, con paciencia y constancia, había mantenido Salazar desde el comienzo de la guerra. La decisión española de concluir con Portugal esa declaración de neutralidad peninsular, significaba la tan ansiada tranquilidad tras los constantes sobresaltos a que les tenía acostumbrados la diplomacia española y, sobre todo, era un éxito diplomático que se apuntaba Portugal ante Inglaterra.

La conclusión del encuentro quedó plasmada en una entente verbal que se hizo pública en el transcurso de los discursos pronunciados durante estos días ${ }^{35}$. Se proclamó en ellos un «Bloque Peninsular de amistad mutua y paz eterna". Las referencias a una futura paz en la guerra europea fueron constantes, así como la toma de posiciones frente a la misma. La decisión de los dos países vecinos de mantenerse alejados de la guerra se explicó como una postura necesaria para «no dejar que se hundiera la civilización occidental». Esa neutralidad quedó matizada, por parte de Portugal, con alusiones a la alianza inglesa y, por su parte, España justificó su «no-beligerancia» en aras al mantenimiento de "los valores cristianos que preservan la civilización occidental». El "Bloque Ibérico" o «Bloque Peninsular» fue un acontecimiento al que ambos países quisieron dar el máximo relieve y, por eso, su tratamiento en la prensa, controlada desde el poder, fue amplio. Los periódicos españoles reflejaron la pretensión de que este Bloque, extendiéndose a otros países católicos y neutrales, sirviese como instrumento para la negociación de una paz en Europa; era, siempre según la prensa, el único medio de evitar el peligro de una expansión comunista en todo el continente. Un diario catalán, al dar la noticia de la entrevista, hizo un curioso comentario: "Si en la guerra civil española hubiese triunfado el Frente Popular, la Península entera estaría en estos momentos ocupada por el ejército alemán» ${ }^{36}$.

Cuando la noticia de las entrevistas apareció en la prensa internacional tuvo una buena acogida. Para la inglesa éste era un acuerdo más, dentro de la línea que mantenía alejada a la Península lbérica de la guerra. Para la del Eje el desembarco aliado en el Norte de África era el

\footnotetext{
${ }^{35}$ Discursos en los banquetes en honor del ministro Jordana los días 19, 20 y 21 de diciembre de 1942, y respuestas de éste. AMAE. Leg. 1375, exp. 16.

${ }^{36}$ La Vanguardia, 22 de diciembre de 1942.
} 
motivo desencadenante de la entente verbal, una forma de garantizarse la no invasión de los aliados, únicos posibles adversarios. De nuevo hacía su aparición el "todos contentos» de Beigbeder. Las diplomacias de Lisboa y Madrid podian sentarse tranquilamente a esperar acontecimientos.

Se puede considerar que el acuerdo del bloque ibérico fue el último eslabón de la cadena en la gran actividad política entre España y Portugal dentro del marco de la segunda guerra mundial. A partir de 1943 la relación diplomática entre los dos países descendió en intensidad. Se debe mencionar, sin embargo, un último momento de equilibrio inestable en la diplomacia peninsular: cuando en el verano de 1943 los ingleses, invocando la alianza que tenían con Portugal, solicitaron al Gobierno de Lisboa utilizar las islas Azores como base aeronáutica y naval. Con ello se rompía el pacto de neutralidad peninsular, al ser utilizado el territorio portugués en favor de los aliados, pero este cambio era inevitable porque Estados Unidos aseguró que, en caso de que no fuese aceptada la concesión de las Azores, estas Islas serían tomadas por la fuerza.

Las consecuencias de los compromisos portugueses podían salpicar a España, sobre todo ante una desconocida relación del Eje. El Pacto Ibérico pasaba a ser el único vínculo diplomático para España, que, en estos momentos, había perdido contacto con Roma y lo estaba perdiendo con Berlín. El 8 de octubre Jordana y Salazar se entrevistaron secretamente en Ciudad Rodrigo, reunión a la que asistieron los respectivos embajadores, Nicolás Franco y Teotonio Pereira. Aunque la cesión de bases en las Azores ya se había hecho pública cuando tuvo lugar el encuentro, el Presidente portugués quiso explicar claramente a España los pormenores de la concesión y, sobre todo, aclarar que no se había faltado a los acuerdos llevados a cabo previamente entre los dos países ${ }^{37}$. Por parte española Jordana interpretó que el acuerdo no afectaba en lo fundamental las relaciones bilaterales hispano-portuguesas. «Se presume, -escribió luego Cárdenas, embajador español en Estados Unidos, a Jordana-, que Portugal debió informar a España y que España no debe haber puesto objeción». Cuando el Duque de Alba informó que el Gobierno británico consideraba que la principal consecuencia de

${ }^{37}$ AFF. Leg. 116, folio 45. Citado por L. SuÁrez Fernandez y, op. cit. pág. 320. Carecemos de actas fehacientes sobre la conversación, pero la documentación posterior confirma que el Presidente portugués quería informar a sus aliados españoles sobre la cesión a los angloamericanos de las Azores. 
la decisión portuguesa sería el traslado de los espías alemanes de Lisboa a Madrid, comentó Jordana a Franco "si no es más que ésto, podemos estar tranquilos» ${ }^{38}$.

Una cuestión más se le presentaba como delicada a España: comunicar a Hitler la noticia. El Gobierno de Madrid presentó, entonces, la concesión como una parte de los gestos orientados a salvaguardar la paz y la neutralidad en la Península lbérica. Después de la entrevista de Ciudad Rodrigo, el embajador español en Berlín, Vidal, invitó al secretario de Estado de la Wilhelmstrasse, Steengracht, a almorzar para explicarle de palabra los acuerdos adoptados: «Me ha escuchado con gran atención lo de nuestras gestiones con Portugal para reducir al mínimo las concesiones -escribió a Madrid-y quedó muy satisfecho de nuestra actitud, aunque recelan de Portugal». Vidal pretendió convencer a la Wilhelmstrasse de que, cediendo, España había conseguido resultados incluso favorables para Alemania al lograr de Salazar que limitase al máximo los efectos de la concesión en Las Azores ${ }^{39}$. La separación de Alemania se consumaba sin grandes obstáculos y ya no hubo necesidad de nuevos Tratados o Acuerdos posteriores.

${ }^{36}$ «Se presume - dice Cárdenas a Jordana en telegrama de 13 de octubre- que Portugal debió informar a España en atención al Pacto lbérico y que España no debe haber puesto objeción". AFF. Leg. 116, folios 16 y 17 y 31-32. Citado en L. SUÁrez Fernández. op. cit.

${ }^{39}$ AFF. Leg. 116, folio 20 y 30 . Ibidem. 